\title{
The functional consequences of Generalized Joint Hypermobility: a cross-sectional study
}

\author{
Mark C Scheper ${ }^{1,2^{*}}$, Janneke E de Vries ${ }^{1}$, Birgit Juul-Kristensen ${ }^{3}$, Frans Nollet ${ }^{2}$ and Raoul hh Engelbert ${ }^{1,2}$
}

\begin{abstract}
Background: Generalized Joint Hypermobility $(G J H)$ has been found to be associated with musculoskeletal complaints and disability. For others GJH is seen as a prerequisite in order to excel in certain sports like dance. However, it remains unclear what the role is of GJH in human performance. Therefore, the purpose of the study was to establish the association between $\mathrm{GJH}$ and functional status and to explore the contribution of physical fitness and musculoskeletal complaints to this association.

Methods: A total of 72 female participants (mean age (SD; range): 19.6 (2.2; 17-24)) were recruited among students from the Amsterdam School of Health Professions (ASHP) $(n=36)$ and the Amsterdam School of Arts (ASA), Academy for dance and theater $(n=36)$ in Amsterdam, The Netherlands. From each participant the following data was collected: Functional status performance (self-reported Physical activity level) and capacity (walking distance and jumping capacity: side hop (SH) and square hop (SQH)), presence of GJH (Beighton score $\geq 4$ ), muscle strength, musculoskeletal complaints (pain and fatigue) and demographic characteristics (age and BMI).

Results: GJH was negatively associated with all capacity measures of functional status. Subjects with GJH had a reduced walking distance $(\mathrm{B}(\mathrm{SE}):-75.5(10.5), \mathrm{p}=<.0001)$ and jumping capacity $(\mathrm{SH}: \mathrm{B}(\mathrm{SE}):-10.10(5.0), \mathrm{p}=.048$, and SQH: $\mathrm{B}$ (SE):-1 1.2(5.1), $\mathrm{P}=.024)$ in comparison to subjects without $\mathrm{GJH}$, when controlling for confounding: age, $\mathrm{BMI}$ and musculoskeletal complaints. In participants with GJH, functional status was not associated with performance measures.

Conclusion: GJH was independently associated with lower walking and jumping capacity, potentially due to the compromised structural integrity of connective tissue. However, pain, fatigue and muscle strength were also important contributors to functional status.
\end{abstract}

Keywords: Generalized Joint Hypermobility, Functional status, Dance, Pain

\section{Background}

An excessive range of motion, which is referred to as Generalized Joint Hypermobility, is present in in 2 to $57 \%$ of the child and adult population [1,2]. It is assumed that $\mathrm{GJH}$ is an expression of laxity of connective tissue, due to genetic alterations in elastic fibers and thus affecting the structural integrity of connective tissue throughout the whole human organism [3]. This in turn, affects the function of multiple organs and structures that are comprised of connective tissue.

\footnotetext{
* Correspondence: m.c.scheper@hva.nl

'Amsterdam School of Health Professions, Education of Physiotherapy, Amsterdam, The Netherlands

${ }^{2}$ Department of Rehabilitation, Academic Medical Center, University of Amsterdam, Amsterdam, The Netherlands

Full list of author information is available at the end of the article
}

Connective tissue laxity is also a clinical feature of specific pathological entities like Ehlers-Danlos Syndrome, Marfan or Ostegenesis Imperfecta [3]. These hereditary diseases of connective tissue (HDCT) are rare and can have serious consequences in terms of disability and in some cases may even result in death. In recent years the genetic origin of collagen diseases has been explored [4-7], whereas also a subgroup of connective tissue disorders was identified. This subgroup of connective tissue disorders shares the typical, although less severe, clinical presentation, but lacks biological markers [8]. These disorders are often referred to as Hypermobility Syndrome (HMS) or Ehlers-Danlos Syndrome (hypermobile type) [9]. The exact prevalence is unknown, and estimates do vary [10]. 
Not all individuals with $\mathrm{GJH}$ are symptomatic, some even take advantage of GJH and excel in certain sports like gymnastics, martial arts or dancing [11,12]. Others experience mild to severe musculoskeletal complaints [13], like joint pain in multiple joints [10], fatigue [13], diminished motor competence [14] and muscle weakness [15]. In a recent study by Scheper et al., GJH was also found to be independently associated with physical deconditioning, fatigue and psychological complaints in professional dancers who are considered to benefit from $\mathrm{GJH}$ in order to perform complex dance routines. These findings and other literature indicate that the consequences of GJH for performance remain poorly understood. If the assumption of connective tissue laxity is correct then GJH should also affect functional status, even in individuals who should excel in functional ability, like professional dancers.

Functional status is a multi-dimensional concept defined as a patient-oriented health outcome which contains aspects of individual daily functioning, including physical, psychological and social factors [16]. Functional status is often used as a primary outcome in a variety of study designs, whereas an operational definition is frequently lacking [17]. It can, however, be operationalized in both capacity and performance measures, where capacity refers to what a patient can do in a standardized environment, and performance to what a person does in daily life [18]. Although often reported by patients and clinicians, the evidence of impairments on functional status in symptomatic GJH is limited, as well as factors influencing functional status.

Weight bearing physical activities like standing, walking and participating in sports and leisure activities might be physically demanding in subjects with symptomatic GJH [19-22]. This is possibly due to the presence of pain, fatigue and reduced physical fitness that could negatively influence functional status [22-24]. However, how much these factors contribute to functional status remains unknown, as do the factors that would enable professional dancers to benefit from GJH instead of adding to functional disability.

Therefore, the aim of the present study was to investigate the association between GJH and functional status, in terms of capacity and performance. In addition the secondary objective was to explore the contribution of physical fitness and musculoskeletal complaints to this association.

\section{Methods}

\section{Subjects}

A convience sample of 72 female participants (mean age(SD); range: $19.6(2.2 ; 17-24))$ were recruited among students from the Amsterdam School of Health Professions (ASHP) $(\mathrm{N}=36)$ and compared to age matched subjects from the Amsterdam School of Arts (ASA), Academy for dance and theater $(\mathrm{N}=36)$ in Amsterdam, The Netherlands. Subjects recruited at ASA were students in their final year of professional dance education and were classified as professional dancers. Subjects were eligible for inclusion when orthopedic, cardiopulmonary-, rheumatological-, neurological conditions or disorders influencing functional status were absent. Secondly, inclusion criteria implied absence of conditions or disorders that render the participant unable to understand the questionnaires or to adhere to the protocol. The study was designed according to the STROBE guidelines [25] (www.strobe-statement.org). Written informed consent was obtained from all participants according to the Declaration of Helsinki [26]. The study was approved by the medical ethical board of the Academic Medical Centre, Amsterdam, the Netherlands.

All outcome measures were classified according to domains of the International Classification of Functioning (ICF) [27], in order to provide a clear description of all outcome measures and their inter-relationship. The ICF is multidimensional model of functioning with activities and participation as the key construct. This model provides a framework to describe limitations associated with an individual's functioning and identifies influencing environmental factors [27].

In the ICF domain body function and structure demographic data were collected regarding age, gender, height and weight. Standing height and weight were measured in a standardized method without wearing heavy clothing and shoes, and rounded to the nearest centimetre and 100 gram, respectively. Body Mass Index (BMI) was calculated with the formula weight/height ${ }^{2}$. All outcome measures were collected by two experienced physical therapists (MCS, JEV) and were assisted by four undergraduate physical therapists. In order to ensure uniformity, all assessors received an 8-week training regime. Data integrity was verified prior to the start of the study for all outcomes in terms of intra-rater reliability. Intrarater reliability (ICC) varied between .81 and .94 and thus exceeding $>.80$, indicating excellent reliability.

\section{Generalized Joint Hypermobility}

The presence of GJH was classified by the Beighton score, with a standardized and reproducible protocol [28]. The Beighton score consists of five clinical maneuvers performed bilaterally and scored dichotomously $(0-1)$. A total score (ranging from $0-9$ ) was derived by summation of all maneuvers: (1) passive opposition of the thumb to the flexor side of the forearm (shoulder $90^{\circ}$ flexed, elbow extended and hand pronated), (2) passive dorsiflexion of the little finger $>90^{\circ}$ (elbow flexed $90^{\circ}$, the forearm and hand pronated resting on a table) (sitting), (3) passive hyperextension of the elbow $>10^{\circ}$ (shoulder $90^{\circ}$ abducted 
and hand supinated), (4) passive hyperextension of the knee $>10^{\circ}$ (standing), (5) forward flexion of the trunk, with knees straight, so that the palms of the hands rest easily on the floor (standing). GJH was defined when a Beigthon score of $\geq 4$ was obtained [29]. Beighton scores were determined by two assessors (MCS, JdV) independently in order to ensure the validity of the $\mathrm{GJH}$ classification, therefore inter-rater reliability was determined. Inter-rater reliability (ICC, $(95 \% \mathrm{CI})$ ) was $.81(.58$ - .94). All visual Beighton observations were verified by the use of goniometer. In addition all subjects were screened independently (blind) by both assessors (MCS, JdV) on the bases of the Brighton criteria for HMS [29]. When the Brighton criteria were not fulfilled and $\mathrm{GJH}$ was accompanied by pain, symptomatic GJH was classified.

\section{Muscle strength}

Muscle strength of the proximal and distal muscles in lower and upper extremities was measured bilaterally in a standardized way [30] with a hand-held dynamometer (Citec, Groningen, The Netherlands). Measurements were consecutively performed three times and the highest value was registered. In the upper extremity, shoulder abductors and grip strength were measured; in the lower extremity, hip flexors, knee extensors and dorsal extensors of the feet were measured. All measurements were performed according to the "break method" with the exception of the knee extension and grip strength. For these measurements the "make method" was applied due to the inability of the assessors to break the generated force of the participant [31]. Total muscle strength was calculated by a summation of all individual muscles (left and right) [31]. After each measurement subjects were asked if they were limited by pain, this was recorded.

\section{Musculoskeletal complaints}

The extent of musculoskeletal complaints was assessed on two aspects: pain intensity and fatigue. Pain intensity was quantified according to the Visual Analog Scale (VAS) expressed in $\mathrm{mm}$, ranging from no pain at all (score: $0 \mathrm{~mm}$ ) to worst pain ever experienced (score: $100 \mathrm{~mm}$ ) [23]. Subjects rated averaged pain intensity experienced in the last two weeks.

Fatigue was quantified by the Checklist Individual Strength (CIS) [32]. The CIS was designed to measure several aspects of fatigue: the subjective experience of fatigue, reduction in motivation, reduction in activity, and reduction in concentration. The CIS has been found reliable and valid in healthy controls, patients with chronic fatigue syndrome and other chronic diseases [32]. Total scores used for analysis were calculated through summation of all sub-items resulting in a score ranging from 0 (no fatigue) to 100 (very severe fatigue) [32].

\section{Functional status: performance}

In the ICF domain activities, performance was defined as the execution of a task or action performed by an individual in real life situations, and is mostly quantified by self-reported properties.

For quantification of the self-reported performance, the Short Questionnaire to Assess Health enhancing physical activity (SQUASH) was used. The SQUASH instrument is designed to assess habitual activity level, and has been shown to be a reliable and valid questionnaire [33]. Data acquired from the SQUASH questionnaire were converted into Metabolic Equivalent Tasks (METS) for each individual domain (mobility, household, occupation and leisure time activities) according to the compendium of physical activities [34]. One MET equals the resting metabolic rate obtained during quiet sitting and equals an approximate oxygen uptake of $3.5 \mathrm{ml} / \mathrm{kg} / \mathrm{min}$. The oxygen expenditure for physical activities ranges, for example, from 0.9 MET for sleeping to 16 METS for running a 6 minutes mile. A total Physical Activity Level was calculated by summation of all individual domains. In addition subjects were questioned if this week was comparable to normal. In the case of a beyond average week, the differences from normal were registered and the Total PAL was adjusted accordingly.

\section{Functional status: capacity}

Capacity is defined as the execution of a task or action performed by an individual in controlled, laboratory like conditions, and was quantified by the Six minute walk test (6MWT) and Jumping capacity tests. These outcomes were chosen derivatives of functional status as they only partly reflect real life activities.

The 6MWT was performed on an 8-meter track in a straight corridor as described by Gulmans et al. [35]. Participants were instructed to cover the largest possible distance in 6 minutes at a self-selected walking speed. Turns were made on both ends of the 8-meter track. The distance walked was recorded with a lap counter. Each time the patient returned to the starting line, the lap counter was clicked once. Every minute the patients were encouraged in a standardized way, and time was recorded with a stopwatch. At the end of the test, the patient was asked to stand still and the distance covered in the final partial lap was measured. Multiplying the number of laps by 16 meters and adding the additional meters of the final partial lap calculated the total distance. The 6MWT was found to be reliable and valid in order to quantify functional capacity [36].

In order to quantify jumping capacity the Side hop test $(\mathrm{SH})$ and the Square Hop test $(\mathrm{SQH})$ were performed [37]. For the $\mathrm{SH}$, the subjects stood on the tested leg, with their hands behind their back, and jumped from side to side between two parallel strips of tape, placed 
$40 \mathrm{~cm}$ apart on the floor. The subjects were instructed to jump as many times as possible during a period of 30 seconds. For the SQH test, the subjects stood on the leg to be tested, with their hands behind their back, outside a $40 \times 40 \mathrm{~cm}$ square marked with tape on the floor. A $10 \mathrm{~cm}$ frame was also marked around the square with tape. For the right leg, the subjects were instructed to jump clockwise in and out of the square as many times as possible during a period of 30 seconds. The number of successful jumps performed, without touching the taped frame, was recorded. Touching the taped frame was recorded as an error and, if more than $25 \%$ of the jumps had errors, a second trial of $30 \mathrm{~s}$ was performed after a 3-min rest period. For the left leg, the subject performed the test in a counter-clockwise mode. The total amount of jumps was used for analysis. After each measurement subjects were asked if they were limited by pain, this was recorded. Only one subject reported to be limited due to pain. When removing this subject from analysis, no effects of that individual was found on the regression models, therefore the subject was retained for analysis.

\section{Statistical analysis}

Statistical analysis was performed in three stages: (1) Assessment of distribution and normality, (2) factor identification and (3) multivariate analysis. Firstly, the skewness of the data was assessed visually and by KolmogorovSmirnoff test. Normally distributed data were expressed by means and standard deviations (SD), whereas not normally distributed data were expressed as median (P50) and interquartile range (P25-P75).
Secondly, factor identification for multivariate analysis was performed by univariate analysis. In order to account for group specific differences (dancer versus nondancer), differences were determined by an independent $\mathrm{t}$-test. Variables with a p-value of $<0.15$ were retained for further analysis [38].

Finally, in order to investigate the association between functional status (dependent variables) and GJH (independent variable), controlled for potential confounding factors, a linear regression analysis was performed. Potential confounding factors were: age, group (dancers vs non-dancer), BMI, muscle strength, pain and fatigue. Results of linear regression are presented in regression coefficients/standard errors (B(SE)) with 95\% confidence intervals $(95 \% \mathrm{CI})$. All statistical analyses were performed in SPSS version 20.0. P-values $<0.05$ were considered to be statistically significant.

\section{Results}

All initially invited subjects were willing to participate and all fulfilled the inclusion criteria and were included in the analysis $(\mathrm{n}=72: 36 / 36)$. The presence of $\mathrm{GJH}$ was significantly higher amongst dancers $(66 \%)$ in comparison to controls $(29 \%)\left(\mathrm{X}^{2}=12.995, \mathrm{p}=.001\right)$. An overview of the included study population is provided in Table 1.

\section{Univariate analyses}

When accounting for differences between dancers and non-dancers (Table 1), dancers showed lower scores on BMI $(\mathrm{T}=3.13, \mathrm{p}=.002)$, higher scores on all capacity measures of functional status: 6MWT $(\mathrm{T}=3.93$, $\mathrm{p}=<.0001), \mathrm{SQH}(\mathrm{T}=3.91, \mathrm{p}=<.0001), \mathrm{SH} \quad(\mathrm{T}=2.49$,

Table 1 Subject characteristics distributed by recruitment location (non-dancer vs. dancer)

\begin{tabular}{|c|c|c|c|c|c|}
\hline \multirow{3}{*}{ Classified with GJH (Beigton $\geq 4: \%$ positive)* } & \multicolumn{2}{|c|}{ Non-dancer $(n=36)$} & \multicolumn{2}{|c|}{ Dancer $(n=36)$} & \multirow{3}{*}{$\begin{array}{l}p \text {-value } \\
p=.004\end{array}$} \\
\hline & \multicolumn{2}{|c|}{10 (29\%) positive vs. 26 (61\%) negative } & \multicolumn{2}{|c|}{$24(66 \%)$ positive vs. $12(34 \%)$ negative } & \\
\hline & Mean (SD) & Range & Mean (SD) & Range & \\
\hline Age $\left(\right.$ years) ${ }^{* *}$ & $20(2)$ & $17.0-24.0$ & $20(2)$ & $17.0-24.0$ & $\mathrm{P}=.999$ \\
\hline BMI $\left(\mathrm{Kg} / \mathrm{m}^{2}\right)$ & $22.3(2.5)$ & $(18.5-28.4)$ & $20.8(1.8)$ & $(16.8-23.5)$ & $p=.002$ \\
\hline \multicolumn{6}{|l|}{ Functional status: Performance } \\
\hline Total PAL (METS) & $168.8(94.4)$ & $16.8-435.2$ & $195.5(104.4)$ & $37.8-491.5$ & $p=.234$ \\
\hline \multicolumn{6}{|l|}{ Functional status: Capacity } \\
\hline 6MWT (m) & $575.3(67.5)$ & $418.5-704$ & $630.8(58.6)$ & $492.0-780.0$ & $\mathrm{p}=<.0001$ \\
\hline SQH (count) & $98.6(24.9)$ & $50.0-144.0$ & $117.2(16.9)$ & $67.0-150.0$ & $\mathrm{p}=<.0001$ \\
\hline SH (count) & $56.8(20.1)$ & 24.0-115.0 & $68.3(21.1)$ & $35.0-125.0$ & $p=.015$ \\
\hline Muscle Strength (N) & $2037.0(337.2)$ & $(1651.7-3313.3)$ & $1988.6(363.2)$ & $(1387.7-2854.0)$ & $p=.605$ \\
\hline Pain intensity (mm) & $43.5(20.2)$ & $(0.0-79.0)$ & $38.3(20.0)$ & $(0.0-72.0)$ & $p=.258$ \\
\hline Fatigue (CIS) & $26(21)$ & $(5-97)$ & $47(17)$ & $(10-83)$ & $\mathrm{p}=<.0001$ \\
\hline
\end{tabular}

Abbreviations: Body Mass Index (BMI), Generalized Joint Hypermobility (GJH), Total Physical Activity level (PAL), Metabolic Equivalent Tasks (METS), Six minute walk test (6MWT), Square Hop (SQH), Side hop (SH), Newton (N), Checklist Individual Strength (CIS). *Chi-square analysis **age matched Significant associations are presented in bold. 
$\mathrm{p}=<.015)$ and experienced increased fatigue $(\mathrm{T}=4.78$, $\mathrm{p}=<.0001)$. Differences in muscle strength and pain intensity did not reach significance $(\mathrm{p}=>.05)$. None of the included subjects reported to be limited due to pain in any of the measurements.

\section{Multivariate analyses}

The results of the multivariate analysis are provided in Table 2, in which the performance outcome is reported in panel $2 \mathrm{a}$ and the capacity measures in panel $2 \mathrm{~b}$ and $2 \mathrm{c}$.

\section{Functional status: performance}

Table 2 (panel 2a) illustrates the linear regression model concerning the association between functional status, expressed as total PAL (performance) and GJH, expressed in Beighton score of $\geq 4$, controlled for confounders. The constructed model explained $6.0 \%$ of all variance, however none of the outcomes reached significance $(\mathrm{p}=>.05)$.

\section{Functional status: capacity}

Table 2 (panel $2 \mathrm{~b}$ and $2 \mathrm{c}$ ) illustrates the linear regression model concerning the association between functional status, expressed in 6MWT and jumping capacity (capacity) and GJH, expressed in Beighton score of $\geq 4$, controlled for confounders.

In the first panel (6MWT) (Table 2b), the constructed model explained $67.8 \%$ of all variance. $6 \mathrm{MWT}$ was significantly negatively associated with GJH (B(SE):-75.5(10.5), $\mathrm{p}=<.0001$ ), indicating lower scores on 6MWT associated with the presence of GJH. Furthermore, this association was negatively modified by BMI (B(SE):-8.4(2.2), $\mathrm{p}<.0001)$ and fatigue $(\mathrm{B}(\mathrm{SE})$ :- $.58(0.28), \mathrm{p}=.044)$. Group (non-dancer vs dancer) (B(SE): 81.5(11.5), $\mathrm{p}=<.0001$ ), and muscle strength $(\mathrm{B}(\mathrm{SE}): .04(0.02), \mathrm{p}=.034)$ were found to be positively associated with $6 \mathrm{MWT}$, indicating dancers to have higher scores on 6MWT, and increased muscle strength. Age $(\mathrm{p}=.488)$ and pain intensity $(\mathrm{p}=.064)$ did not reach significance $(\mathrm{p}=>.05)$.

In the second panel on jumping capacity $(\mathrm{SH}, \mathrm{SQH})$ (Table 2c) similar results were found. When using SQH as dependent variable, $39.9 \%$ of all variance was explained by the model. SQH was significantly negatively associated with GJH (B(SE):-11.2(5.1), $\mathrm{p}=.029$ ), indicating the presence of GJH to be associated with lower scores on $\mathrm{SQH}$. In addition, pain intensity was negatively associated with $\mathrm{SQH}$, indicating lower scores on $\mathrm{SQH}$ with increasing pain intensity level $(\mathrm{B}(\mathrm{SE}):-0.26(0.1), \mathrm{p}=.033)$. Dancing status was positively associated with $\mathrm{SQH}$, with dancers scoring higher on $\mathrm{SQH}$ than non-dancers (B(SE): 18.1(5.5), $\mathrm{p}=.002$ ). Muscle strength was found to be positively associated with $\mathrm{SQH}(\mathrm{B}(\mathrm{SE})$ : $0.02(0.1)$, $\mathrm{p}=.009)$. The remaining factors also failed to reach significance $(\mathrm{p}=>.05)$.
When using $\mathrm{SH}$ as the dependent variable, similar results were found. The model explained $34.9 \%$ of all variance. $\mathrm{SH}$ scores were found to be significantly negatively associated with the presence of $\mathrm{GJH}(\mathrm{B}(\mathrm{SE})$ :-10.1(5.0), $\mathrm{p}=.048$ ), indicating lower score on $\mathrm{SH}$ when $\mathrm{GJH}$ was present. Again dancers showed higher scores on the $\mathrm{SH}$ in comparison to non-dancers (B(SE): 15.3(5.5), $\mathrm{p}=.007$ ). The remaining factors did not reach significance $(\mathrm{p}=>.05)$.

\section{Discussion}

Based on the presented data and after correction for confounders, GJH was associated with a decrease in functional status in terms of capacity, measured as walking distance and jumping capacity. No significant associations were found between $\mathrm{GJH}$ and a decrease in functional status in terms of performance (self-reported PAL). When regarding the capacity measures, both BMI and fatigue were found to be negative influencing factors on 6MWT. In contrast, increases in muscle strength and being a professional dancer were found to be positively associated with higher capacity of $6 \mathrm{MWT}$ and jump capacity.

The current sample consisted of young female adults recruited among healthcare students and a selected group of professional performing arts students (dancers). These two populations were found to differ on several clinical characteristics. First of all, dancers had significantly higher Beighton scores and lower scores on BMI, indicating that on average these subjects are slimmer and more flexible. An explanation for the observed difference can be found in the admission criteria for the professional dance education, where students with high flexibility and slim posture are more likely to be admitted. Despite the high flexibility and the significantly higher levels of fatigue of the included dancers, these individuals showed higher levels of physical capacity (6MWT, jumping capacity).

Besides the selection by flexibility and slender posture, dancers were admitted to the education when they excel in performing complex choreographs. We postulate that as result of the stringent selection criteria and training for professional dancers, they were able to perform better on all capacity measures, and especially on the jumping tests that also rely heavily on general gross motor competences. Previous studies on children and adults diagnosed with symptomatic forms of hypermobility have been found to have less motor control [14] and proprioception. Combined with a loss in physical fitness in terms of muscle strength and cardiovascular exercise capacity $[15,30]$, this may lead to functional decline in individuals with symptomatic hypermobility. However, in the current study the presence of GJH was independently associated with a lower physical capacity (both 
Table 2 Multivariate regression models

\begin{tabular}{|c|c|c|c|c|c|c|}
\hline \multirow{3}{*}{$\begin{array}{l}\text { Panel 2a } \\
\text { Dependent } \\
\text { Total PAL }\end{array}$} & \multicolumn{6}{|c|}{ Functional status (performance) } \\
\hline & \multirow{2}{*}{$\begin{array}{c}\text { Predictor } \\
\text { Age }\end{array}$} & \multirow{2}{*}{$\begin{array}{c}\text { B (SE) } \\
-1.89(5.6)\end{array}$} & \multirow{2}{*}{$\frac{B}{-0.04}$} & \multicolumn{2}{|c|}{$95 \% \mathrm{Cl}$ for $\mathrm{B}$} & \multirow{2}{*}{$\begin{array}{l}\text { p-value } \\
p=.738\end{array}$} \\
\hline & & & & -13.10 & 9.31 & \\
\hline & Non-dancer vs dancer & $37.71(29.3)$ & 0.20 & -20.68 & 96.11 & $p=.202$ \\
\hline & BMI & $4.06(5.6)$ & 0.09 & -7.29 & 15.41 & $p=.478$ \\
\hline & GJH (Beighton $\geq 4$ ) & $-19.69(26.9)$ & -0.10 & -73.33 & 33.94 & $p=.467$ \\
\hline & Muscle Strength $(\mathrm{N})$ & $-0.04(0.5)$ & -0.16 & -0.14 & 0.05 & $p=.373$ \\
\hline & Pain intensity (mm) & $-0.364(0.6)$ & -0.07 & -1.66 & 0.05 & $p=.576$ \\
\hline & Fatigue (CIS) & $-0.03(0.7)$ & -0.07 & -1.47 & 1.40 & $p=.964$ \\
\hline Panel 2b & \multicolumn{6}{|c|}{ Functional status (capacity): Walking distance } \\
\hline Dependent & Predictor & $\mathrm{B}(\mathrm{SE})$ & B & \multicolumn{2}{|c|}{$95 \% \mathrm{Cl}$ for $\mathrm{B}$} & p-value \\
\hline \multirow[t]{8}{*}{$\overline{6 \mathrm{MWT}^{1}}$} & Age & $1.53(2.2)$ & 0.05 & -2.85 & 5.91 & $p=.488$ \\
\hline & Non-dancer vs dancer & $81.5(11.5)$ & 0.59 & 58.6 & 104.3 & $p=<.0001$ \\
\hline & BMI & $-8.4(2.2)$ & -0.28 & -12.8 & -3.9 & $p=<.0001$ \\
\hline & GJH (Beighton $\geq 4$ ) & $-75.5(10.5)$ & -0.55 & -96.5 & -54.5 & $p=<.0001$ \\
\hline & Muscle Strength (N) & $0.04(0.02)$ & 0.20 & 0.03 & 0.08 & $p=.034$ \\
\hline & Pain intensity (mm) & $0.48(0.25)$ & 0.14 & -0.29 & 0.98 & $p=.064$ \\
\hline & Fatigue (CIS) & $-0.58(0.28)$ & -0.18 & -1.14 & -0.02 & $p=.044$ \\
\hline & \multicolumn{6}{|c|}{${ }^{1}$ Regression equitation: $6 \mathrm{MWT}=81.5($ dance: $\left.0 / 1)+-.8 .4(\mathrm{BMI})+-.75 .5(\mathrm{GJH}: 0 / 1)\right)+.04($ Muscle $)+-.58($ fatigue $)$} \\
\hline Panel 2c & \multicolumn{6}{|c|}{ Functional status (capacity): Jumping capacity } \\
\hline Dependent & Predictor & B (SE) & B & & & p-value \\
\hline \multirow[t]{7}{*}{$\mathrm{SQH}^{2}$} & Age & $.44(1.1)$ & 0.04 & -1.66 & 2.54 & $p=.678$ \\
\hline & Non-dancer vs dancer & 18.1(5.5) & 0.39 & 7.12 & 29.03 & $p=.002$ \\
\hline & $\mathrm{BMl}$ & $-0.81(1.1)$ & -0.08 & -2.94 & 1.32 & $p=.451$ \\
\hline & GJH (Beighton $\geq 4$ ) & $-11.2(5.1)$ & -0.24 & -21.29 & -1.16 & $p=.029$ \\
\hline & Muscle Strength (N) & $0.02(0.1)$ & 0.36 & 0.01 & 0.04 & $p=.009$ \\
\hline & Pain intensity $(\mathrm{mm})$ & $-0.26(0.1)$ & -0.23 & -0.49 & -0.02 & $p=.033$ \\
\hline & Fatigue (CIS) & $-0.08(0.1)$ & -0.07 & -0.35 & 0.19 & $p=.573$ \\
\hline \multirow[t]{10}{*}{$\mathrm{SH}^{3}$} & Age & $1.14(1.1)$ & 0.11 & -0.95 & 3.24 & $p=.279$ \\
\hline & Non-dancer vs dancer & $15.3(5.5)$ & 0.34 & 4.35 & 26.17 & $p=.007$ \\
\hline & BMl & $-1.49(1.1)$ & -0.17 & -3.61 & 0.63 & $p=.165$ \\
\hline & GJH (Beighton $\geq 4$ ) & $-10.1(5.0)$ & -0.22 & -20.19 & -0.08 & $p=.048$ \\
\hline & Muscle Strength (N) & $0.01(0.01)$ & 0.06 & -0.01 & 0.02 & $p=.650$ \\
\hline & Pain intensity (mm) & $-0.12(0.1)$ & -0.11 & -0.36 & 0.12 & $p=.322$ \\
\hline & Fatigue (CIS) & $-0.14(0.1)$ & -0.14 & -0.41 & 0.12 & $p=.289$ \\
\hline & \multicolumn{6}{|c|}{${ }^{2}$ Regression equitation: $\mathrm{SQH}=18.1($ Dance: $0 / 1)+-11.2(\mathrm{GJH}: 0 / 1)+.02($ Muscle $)+-.3($ pain $)$} \\
\hline & \multicolumn{6}{|c|}{${ }^{3}$ Regression equitation: $\mathrm{SH}=15.3($ Dance: $0 / 1)+-10.1(\mathrm{GJH}: 0 / 1)$} \\
\hline & \multicolumn{6}{|c|}{ Note: Total PAL: $R^{2}: .060,6 M W T: R^{2}=.678$, SQH: $R^{2}=.399$, SH: $R^{2}=.349$} \\
\hline
\end{tabular}

Abbreviations: $\beta$ (standardized beta), Body Mass Index (BMI), Generalized Joint Hypermobility (GJH), Total Physical Activity level (PAL), Metabolic Equivalent Tasks (METS), Six minute walk test (6MWT), Square Hop (SQH), Side hop (SH), Newton (N), Checklist Individual Strength (CIS) Significant associations are presented in bold.

6MWT and jumping capacity), even in physically welltrained professional dancers. This could imply that connective tissue laxity, in terms of GJH, is a risk factor for functional decline rather than the consequence of deconditioning [39].
From the current data we can conclude that in females, muscle strength is a promoting factor in regard to functional status in terms of 6MWT, and furthermore, ascribes the potential benefit of strength training for improved capacity. However, due to the design of the 
study, the current study lacks methodological strength to prove such an assumption. Besides muscle weakness, reduced cardiovascular exercise tolerance has also been reported in literature in both symptomatic [30] and nonsymptomatic GJH [11]. This was not included in the current analysis, however most functional activities do not require maximum exercise tolerance like effort, and even more so, most individuals rarely engage in sustained maximum cardiovascular efforts. When looking at the levels of muscle strength and functional capacity in dancers classified with $\mathrm{GJH}$, these were considerably higher in comparison to non-dancers with GJH. Higher levels of physical fitness and motor competence could explain this difference and may be the result of training which is in line with current literature [40].

Pain intensity was not found to be a factor of influence on $6 \mathrm{MWT}$. This could be related to the low intensity and stable, cyclic nature of walking like in the 6MWT. Pain intensity, which was a negatively influencing factor on $\mathrm{SQH}$, might have been a more important factor in more dynamic activities like $\mathrm{SQH}$, exerting more forces on joint surfaces, especially in movements requiring axial rotational forces.

According to the multivariate analyses, GJH had a negative contribution in all capacity variables. The presence of GJH, which could be the result of abnormal connective tissue laxity, may result in higher demands on active joint stabilization mechanisms [41,42]. In combination with proprioceptive inaccuracy, during highly coordinative tasks like walking, demanding adaptive strategies like co-contraction or prolonged activation of certain muscle groups are required to stabilize joints during these activities [43]. Further, higher energy demands may be required, which could lead to fatigue [44]. In our data next to $\mathrm{GJH}$, fatigue was also a negative contributor to the walking distance supporting this theory.

We found a profound difference between performance and capacity, which could be explained by the use of questionnaires which are based on subjective experience and recall. The lack of association in performance could be the result of estimation bias due to recall. In addition capacity measures are only able to reflect activity impairments partially as they do not account for environmental factors. The presence of recall bias could be avoided, while accounting for environmental factors, by the use of objective performance measures like 3d accelerometry. Although not possible in the current study due to time constraints, this would be recommended for future studies.

When interpreting the presented results, the following limitations should be considered. Firstly, the included population was selected from healthcare students, who may attend more to issues of healthy living when compared to the general population, as well as professional dance students, who have highly demanding physical routines in their daily life. In addition, the current included population was limited to only females due to the lack of available male dancers at time of inclusion. This limits the generalizability of these results to the general population. Still, these results do illustrate that biomechanical factors like GJH have direct consequences for functional status, however the magnitude of that effect could differ between populations, with this group being a high risk population. Secondly, the used outcomes of functional status are not dance specific, due to the issues of comparability between dancers and non-dancers. The effect of GJH on dancing itself might differ and should be investigated. Still, both walking and jumping are also applicable to dancers and could indicate that also GJH can have profound effects on dancing and might even be larger due to the high demands on joint stability during dancing. Currently the use of the Beighton score in order to determine GJH is highly debated. Although the Beighton score is still considered to be the "gold standard" for classifying GJH, aspects of its operationalization and the validity of the cut-off values are still in need of further research and a revision of the way $\mathrm{GJH}$ is determined is needed [40]. Thirdly, environmental and psychological factors were not incorporated in the current study. Social status, peer pressure, kinesiophobia and (pain) coping strategies could explain the discrepancies between the performance and capacity measures of functional status [45]. However, this is beyond the scope of the current paper but could prove to be a vital area of future research in order to fully understand the interaction between functional status and the human organism in its own individual context. Such knowledge is critical in order to develop effective treatment modalities that are able to diminish activity impairments for subjects diagnosed with symptomatic forms of GJH. It may also be important for treatment of other musculoskeletal diseases. Finally, based on the study design these results offer no causative evidence, therefore, these observations need to be replicated in longitudinal observational studies incorporating individuals with both symptomatic and non-symptomatic GJH.

\section{Conclusion}

We conclude, that GJH in females was associated with a decrease in functional status in terms of capacity, measured as walking distance and jumping capacity.

$\mathrm{GJH}$ is a factor to consider when assessing functional status in terms of walking and jumping capacity, possibly due to altered joint biomechanics, compromised by structural integrity of connective tissue. Incorporating the assessment of musculoskeletal complaints (pain), fatigue, and muscle strength could provide additional clinically relevant information. However, the role of connective tissue laxity, expressed by $\mathrm{GJH}$, for functional status is still poorly understood. 


\section{Abbreviations}

GJH: Generalized joint Hypermobility; BMI: Body Mass Index; PAL: Total Physical Activity level; METS: Metabolic Equivalent Tasks; 6MWT: Six minute walk test; SQH: Square Hop; SH: Side Hop; N: Newton; CIS: Checklist Individual Strength.

\section{Competing interests}

The authors declare that they have no competing interests.

\section{Authors' contributions}

MCS was involved in the conception of the design, data collection, data analysis, drafted the manuscript. JEV was involved in data collection, data analysis and assisted in drafting the manuscript. BJK assisted in the data analysis and the drafting of the manuscript. FN was involved in the drafting of the manuscript and the conception of the design, $\mathrm{RHHE}$ was the coordinating researcher and was involved in the conception of the design and the drafting of the manuscript. All authors read and approved the final manuscript.

\section{Acknowledgements}

The authors would like to thank all the students from the Amsterdam School of Arts and the Amsterdam School of Health Professions for their participation and assistance during this study. Also the authors would like to thank Lobke Mienis, Erzi Hoogveld, Margot Rijven, Menno de Vries for their efforts in order to realize this study.

\section{Author details}

${ }^{1}$ Amsterdam School of Health Professions, Education of Physiotherapy, Amsterdam, The Netherlands. ${ }^{2}$ Department of Rehabilitation, Academic Medical Center, University of Amsterdam, Amsterdam, The Netherlands. ${ }^{3}$ University of Southern Denmark, Institute of Sports Science and Clinical Biomechanics, Research Unit for Musculoskeletal Function and Physiotherapy, Odense, Denmark.

Received: 15 February 2014 Accepted: 14 July 2014

Published: 21 July 2014

\section{References}

1. Remvig L, Jensen DV, Ward RC: Epidemiology of general joint hypermobility and basis for the proposed criteria for benign joint hypermobility syndrome: review of the literature. J Rheumatol 2007, 34:804-809.

2. Rikken-Bultman DG, Wellink L, van Dongen PW: Hypermobility in two Dutch school populations. Eur J Obstet Gynecol Reprod Biol 1997, 73:189-192.

3. Remvig L, Engelbert RH, Berglund B, Bulbena A, Byers PH, Grahame R, Juul-Kristensen B, Lindgren KA, Uitto J, Wekre LL: Need for a consensus on the methods by which to measure joint mobility and the definition of norms for hypermobility that reflect age, gender and ethnic-dependent variation: is revision of criteria for joint hypermobility syndrome and Ehlers-Danlos syndrome hypermobility type indicated? Rheumatology 2011, 50:2.

4. Grahame R: Heritable disorders of connective tissue. Baillieres Best Pract Res Clin Rheumatol 2000, 14:345-361.

5. Hakim AJ, Cherkas LF, Grahame R, Spector TD, MacGregor AJ: The genetic epidemiology of joint hypermobility: a population study of female twins. Arthritis Rheum 2004, 50:2640-2644.

6. Malfait F, De Paepe A: Molecular genetics in classic Ehlers-Danlos syndrome. Am J Med Genet C Semin Med Genet 2005, 139C:17-23.

7. Malfait F, Hakim AJ, De Paepe A, Grahame R: The genetic basis of the joint hypermobility syndromes. Rheumatology (Oxford) 2006, 45:502-507.

8. Tinkle BT, Bird HA, Grahame R, Lavallee M, Levy HP, Sillence D: The lack of clinical distinction between the hypermobility type of Ehlers-Danlos syndrome and the joint hypermobility syndrome (a.k.a. hypermobility syndrome). Am J Med Genet A 2009, 149A:2368-2370.

9. Remvig L, Engelbert RH, Berglund B, Bulbena A, Byers PH, Grahame R, Juul-Kristensen B, Lindgren KA, Uitto J, Wekre LL: Need for a consensus on the methods by which to measure joint mobility and the definition of norms for hypermobility that reflect age, gender and ethnic-dependent variation: is revision of criteria for joint hypermobility syndrome and Ehlers-Danlos syndrome hypermobility type indicated? Rheumatology 2011, 50:1169-1171.
10. Grahame R: Hypermobility: an important but often neglected area within rheumatology. Nat Clin Pract Rheumatol 2008, 4:522-524.

11. Scheper MC, de Vries JE, de Vos R, Verbunt J, Nollet F, Engelbert RH: Generalized joint hypermobility in professional dancers: a sign of talent or vulnerability? Rheumatology 2013, 52:651-658.

12. Day H, Koutedakis $Y$, Wyon MA: Hypermobility and dance: a review. Int $J$ Sports Med 2011, 32:485-489.

13. Voermans NC, Knoop H, van de Kamp N, Hamel BC, Bleijenberg G, van Engelen BG: Fatigue is a frequent and clinically relevant problem in Ehlers-Danlos syndrome. Semin Arthritis Rheum 2010, 40:267-274.

14. Hanewinkel-van Kleef YB, Helders PJ, Takken T, Engelbert RH: Motor performance in children with generalized hypermobility: the influence of muscle strength and exercise capacity. Pediatr Phys Ther 2009, 21:194-200.

15. Engelbert RH, Bank RA, Sakkers RJ, Helders PJ, Beemer FA, Uiterwaal CS: Pediatric generalized joint hypermobility with and without musculoskeletal complaints: a localized or systemic disorder? Pediatrics 2003, 111:e248-e254

16. Wang TJ: Concept analysis of functional status. Int J Nurs Stud 2004, 41:457-462.

17. Leidy NK: Using functional status to assess treatment outcomes. Chest 1994, 106:1645-1646.

18. Jette AM: Toward a common language for function, disability, and health. Phys Ther 2006, 86:726-734.

19. Berglund B, Mattiasson AC, Nordstrom G: Acceptance of disability and sense of coherence in individuals with Ehlers-Danlos syndrome. J Clin Nurs 2003, 12:770-777.

20. Rombaut L, Malfait F, Cools A, De Paepe A, Calders P: Musculoskeletal complaints, physical activity and health-related quality of life among patients with the Ehlers-Danlos syndrome hypermobility type. Disabil Rehabil 2010, 32:1339-1345.

21. Rombaut L, De Paepe A, Malfait F, Cools A, Calders P: Joint position sense and vibratory perception sense in patients with Ehlers-Danlos syndrome type III (hypermobility type). Clin Rheumatol 2010, 29:289-295.

22. Voermans NC, Knoop H, Bleijenberg G, van Engelen BG: Pain in ehlers-danlos syndrome is common, severe, and associated with functional impairment. J Pain Symptom Manage 2010, 40:370-378.

23. Fatoye F, Palmer S, Macmillan F, Rowe $P$, van der Linden M: Pain intensity and quality of life perception in children with hypermobility syndrome. Rheumatol Int 2010, 32:1277-1284.

24. Voermans NC, Knoop H, Bleijenberg G, van Engelen BG: Fatigue is associated with muscle weakness in Ehlers-Danlos syndrome: an explorative study. Physiotherapy 2011, 97:170-174.

25. von Elm E, Altman DG, Egger M, Pocock SJ, Gotzsche PC, Vandenbroucke JP, Initiative S: The Strengthening the Reporting of Observational Studies in Epidemiology (STROBE) statement: guidelines for reporting observational studies. Lancet 2007, 370:1453-1457.

26. Vollmann J, Winau R: Informed consent in human experimentation before the Nuremberg code. BMJ 1996, 313:1445-1449.

27. Atkinson $\mathrm{HL}$, Nixon-Cave $\mathrm{K}$ : A tool for clinical reasoning and reflection using the international classification of functioning, disability and health (ICF) framework and patient management model. Phys Ther 2011, 91:416-430

28. Juul-Kristensen B, Rogind $H$, Jensen DV, Remvig L: Inter-examiner reproducibility of tests and criteria for generalized joint hypermobility and benign joint hypermobility syndrome. Rheumatology 2007, 46:1835-1841.

29. Grahame R, Bird HA, Child A: The revised (Brighton 1998) criteria for the diagnosis of benign joint hypermobility syndrome (BJHS). J Rheumatol 2000, 27:1777-1779.

30. Engelbert RH, van Bergen M, Henneken T, Helders PJ, Takken T: Exercise tolerance in children and adolescents with musculoskeletal pain in joint hypermobility and joint hypomobility syndrome. Pediatrics 2006, 118:e690-e696.

31. Koblbauer IF, Lambrecht $Y$, van der Hulst ML, Neeter C, Engelbert RH, Poolman RW, Scholtes VA: Reliability of maximal isometric knee strength testing with modified hand-held dynamometry in patients awaiting total knee arthroplasty: useful in research and individual patient settings? A reliability study. BMC Musculoskelet Disord 2011, 12:249.

32. Vercoulen JH, Swanink CM, Fennis JF, Galama JM, van der Meer JW, Bleijenberg G: Dimensional assessment of chronic fatigue syndrome. J Psychosom Res 1994, 38:383-392. 
33. Wendel-Vos GC, Schuit AJ, Saris WH, Kromhout D: Reproducibility and relative validity of the short questionnaire to assess health-enhancing physical activity. J Clin Epidemiol 2003, 56:1163-1169.

34. Ainsworth BE, Haskell WL, Whitt MC, Irwin ML, Swartz AM, Strath SJ, O'Brien WL, Bassett DR Jr, Schmitz KH, Emplaincourt PO, Jacobs DR Jr, Leon AS: Compendium of physical activities: an update of activity codes and MET intensities. Med Sci Sports Exerc 2000, 32:S498-S504.

35. Gulmans VA, van Veldhoven NH, de Meer K, Helders PJ: The six-minute walking test in children with cystic fibrosis: reliability and validity. Pediatr Pulmonol 1996, 22:85-89.

36. Bellet RN, Adams L, Morris NR: The 6-minute walk test in outpatient cardiac rehabilitation: validity, reliability and responsiveness-a systematic review. Physiotherapy 2012, 98:277-286.

37. Gustavsson A, Neeter C, Thomee P, Silbernagel KG, Augustsson J, Thomee R, Karlsson J: A test battery for evaluating hop performance in patients with an $\mathrm{ACL}$ injury and patients who have undergone $\mathrm{ACL}$ reconstruction. Knee Surg Sports Traumatol Arthrosc 2006, 14:778-788.

38. Freedman DA: A note on screening regression equations. Am Statistician 1983, 2:4.

39. Russek LN: Hypermobility syndrome. Phys Ther 1999, 79:591-599.

40. Scheper MC, Engelbert RH, Rameckers EA, Verbunt J, Remvig L, Juul-Kristensen B: Children with generalised joint hypermobility and musculoskeletal complaints: state of the art on diagnostics, clinical characteristics, and treatment. Bio Med Res Int 2013, 2013:121054.

41. Fatoye FA, Palmer S, van der Linden ML, Rowe PJ, Macmillan F: Gait kinematics and passive knee joint range of motion in children with hypermobility syndrome. Gait Posture 2011, 33:447-451.

42. Ferrell WR, Tennant N, Sturrock RD, Ashton L, Creed G, Brydson G, Rafferty D: Amelioration of symptoms by enhancement of proprioception in patients with joint hypermobility syndrome. Arthritis Rheum 2004, 50:3323-3328

43. Ortiz A, Olson SL, Etnyre B, Trudelle-Jackson EE, Bartlett W, Venegas-Rios HL: Fatigue effects on knee joint stability during two jump tasks in women. J Strength Cond Res 2010, 24:1019-1027.

44. Missenard O, Mottet D, Perrey S: The role of cocontraction in the impairment of movement accuracy with fatigue. Exp Brain Res 2008, 185:151-156.

45. Huijnen IP, Verbunt JA, Peters ML, Delespaul P, Kindermans HP, Roelofs J, Goossens M, Seelen HA: Do depression and pain intensity interfere with physical activity in daily life in patients with Chronic Low Back Pain? Pain 2010, 150:161-166.

\section{doi:10.1186/1471-2474-15-243}

Cite this article as: Scheper et al:: The functional consequences of Generalized Joint Hypermobility: a cross-sectional study. BMC Musculoskeletal Disorders 2014 15:243.

\section{Submit your next manuscript to BioMed Central and take full advantage of:}

- Convenient online submission

- Thorough peer review

- No space constraints or color figure charges

- Immediate publication on acceptance

- Inclusion in PubMed, CAS, Scopus and Google Scholar

- Research which is freely available for redistribution 